\title{
Efficacy of pneumatic dilatation for the treatment of idiopatic achalasia: a single-center experience
}

Emanuele Sinagra 1,2,3, Dario Raimondo ${ }^{1}$, Luigi Maria Montalbano ${ }^{4}$, Cristina Linea ${ }^{4}$, Marco Giunta ${ }^{4}$, Georgios Amvrosiadis 5, Gaetano Cristian Morreale ${ }^{4}$, Marco Ciofalo ${ }^{6}$, Aroldo Gabriele Rizzo ${ }^{7}$, Giovanni Tomasello ${ }^{8,3}$, Attilio Ignazio Lo Monte ${ }^{8}$, Gennaro D’Amico ${ }^{4}$

${ }^{1}$ Gastroenterology and Endoscopy Unit, Fondazione Istituto San Raffaele-G.Giglio, Contrada Pietra Pollastra Pisciotto, 90015 Cefalù, Italy

${ }^{2}$ PhD course in Surgical Biotechnology and Regenerative Medicine, University of Palermo, Italy

${ }^{3}$ Euro-Mediterranean Institute of Science and Technology (IEMEST), Palermo, Italy

${ }^{4}$ Ospedali Riuniti Villa Sofia - Vincenzo Cervello, Gastroenterology Unit, via Trabucco 180, 90100, Palermo, Italy

${ }^{5}$ DIBIMIS, Ospedali Riuniti Villa Sofia - Vincenzo Cervello, Division of Internal Medicine, via trabucco 180, 90100, Palermo, Italy

${ }^{6}$ AOUP Paolo Giaccone, University of Palermo, School of Medicine, Palermo, Italy

${ }^{7}$ Ospedali Riuniti Villa Sofia - Vincenzo Cervello, Pathology Unit, via Trabucco 180, 90100, Palermo, Italy

${ }^{8}$ Department of Surgical and Oncological Disciplines, School of Medicine, University of Palermo, Italy

Correspondence: Emanuele Sinagra

E-mail: emanuelesinagra83@googlemail.com

Received: January 07, 2015

Published online: March 16, 2015

Pneumatic dilatation (PD) and Surgical Miotomy (SM) are presently the best treatments for untreated achalasia, with similar efficacy. There is no information on the relative efficacy of PD in younger compared to older patients. Aim of our study was to compare success rate and safety of PD in patients under fifty years old and in those over fifty years old affected by achalasia. Twenty consecutive symptomatic patients were treated in our Unit with graded PD under fluoroscopic view. Five male and 15 female with a median age of 47 years were treated. Twelve patients were less than fifty years old (group I) while 8 were older (group II). Median dysphagia questionnaire score was 14 and 13 in group I and II respectively. Technical success was achieved in all patients. Seven patients were previously treated through other techniques. In group I all patients achieved a complete remission of symptoms with significant decrease of the dysphagia questionnaire score (3). In group II all patients achieved a complete remission of symptoms with significant decrease of the dysphagia questionnaire score (4.5) but 3 of them repeated the procedure. In boths groups the efficacy of the dilation was radiologically confirmed. Neither early nor late complications were reported in either groups. In our experience PD was an effective and safe procedure both in young and old patients although the older group had more recurrences, all successfully re-dilated.

Keywords: esophageal achalasia; pneumatic dilation; surgical miotomy

To cite this article: Emanuele Sinagra, et al. Efficacy of pneumatic dilatation for the treatment of idiopatic achalasia: a single-center experience. Abdomen 2015; 2: e512. doi: 10.14800/Abdomen.512.

\section{Introduction}

Achalasia is a primary esophageal motility disorder which is characterized by impaired relaxation of lower esophageal sphincter and aperistalsis of esophagus. Up to now, the mainstay of treatment of achalasia is the mechanical disruption of the lower esophageal sphincter muscle fibers by either endoscopic pneumatic dilation (PD) or surgical myotomy $(\mathrm{SM})$, in order to reduce the lower esophageal sphincter pressure ${ }^{[1]}$. 
However, there is no information on the relative efficacy of PD in younger compared to older patients. Aim of our study was to compare success rate and safety of PD in patients under fifty years old and in those over fifty years old affected by achalasia.

\section{Patients and methods}

Twenty consecutive symptomatic patients were treated in our Unit with graded PD trough Rigiflex balloons (®Boston Scientific) under fluoroscopic view. All patients were previously evaluated with upper endoscopy and x-ray upper gastrointestinal transit. When indicated esophageal manometry was also performed. All patients signed an informed consent and filled in a dysphagia questionnaire (table 1) before the procedure. All procedures were performed under conscious sedation monitoring blood pressure, heart rate and oximetry. Patients were hospitalized and afterwards followed-up as outpatients in order to assess the clinical benefit or the onset of late complication.

Five male and 15 female with a median age of 47 years (range 21-82) were treated. Twelve patients were less than fifty years old (group I) while 8 were older (group II). Median dysphagia questionnaire score was 14 and 13 in group I and II respectively. Technical success was achieved in all patients obtaining a final dilation up to $35 \mathrm{~mm}$. Seven patients were previously treated as follow: 4 with medical therapy, 2 trough botulin injection and 1 with HM. The median follow-up was 34.5 months (range 2-120).

\section{Results}

In group I all patients achieved a complete remission of symptoms with significant decrease of the dysphagia questionnaire score (median value: 3 ). In group II all patients achieved a complete remission of symptoms with significant decrease of the dysphagia questionnaire score (median value: 4.5 ) but 3 of them repeated the procedure after a median of 4.5 months, after the new assessment of Lower Esophageal Sphinter (LES) pressure. In both groups the efficacy of the dilation was radiologically confirmed. Neither early nor late complication were reported in either groups. In group II one patient died from esophageal carcinoma (histology before dilation was negative) and 1 from gallbladder carcinoma.

\section{Discussion}

In our experience PD was an effective and safe procedure both in young and old patients although the older group had more recurrences, all successfully re-dilated.

Table 1. Dysphagia questionnaire

\begin{tabular}{|c|c|c|}
\hline \multirow[t]{4}{*}{1} & \multirow[t]{4}{*}{ Difficulty swallowing liquids } & 0 never \\
\hline & & $1<1 \times$ week \\
\hline & & 2 several times/week \\
\hline & & 3 every day \\
\hline \multirow[t]{5}{*}{2} & \multirow[t]{5}{*}{ Difficulty swallowing solids } & 0 never \\
\hline & & $1<1 \times$ week \\
\hline & & 2 several times/week \\
\hline & & 3 every day \\
\hline & & 4 several times/ day \\
\hline \multirow[t]{4}{*}{3} & \multirow[t]{4}{*}{ Character of swallowing difficulty } & 0 never \\
\hline & & 1 solids sticks briefly \\
\hline & & 2 solids only clear with liquids \\
\hline & & 3 solids cause vomiting \\
\hline \multirow[t]{3}{*}{4} & \multirow[t]{3}{*}{ Present weight } & 1 increased \\
\hline & & 2 same \\
\hline & & 3 solids cause vomiting \\
\hline \multirow[t]{2}{*}{5} & \multirow[t]{2}{*}{ Chest pain } & 0 absent \\
\hline & & 1 present \\
\hline \multirow[t]{2}{*}{6} & \multirow[t]{2}{*}{ extraoesophageal symptoms } & 0 absent \\
\hline & & 1 present \\
\hline \multirow[t]{3}{*}{7} & \multirow[t]{3}{*}{ use of PPI } & 0 none \\
\hline & & 1 less than 3 months \\
\hline & & 2 more than 3 months \\
\hline \multirow[t]{4}{*}{8} & \multirow[t]{4}{*}{ HB } & $1>12$ \\
\hline & & $210-12$ \\
\hline & & $310-8$ \\
\hline & & $4<8$ \\
\hline
\end{tabular}

As aforementioned, PD of the LES in patients with achalasia is performed to fracture the muscularis propria. PD with a rigid balloon across the LES has been shown to be an effective and inexpensive technique, while the use of bougienage or standard balloon dilation resulted to be typically ineffective in achalasia ${ }^{[2,3]}$. Usually the balloon is positioned across the LES using a guidewire and fluoroscopy. Investigators have also performed PD through a direct visualization rather than fluoroscopy to limit radiation exposure as well as to improve clinical remission and complications; however no differences were found, in terms of complications or response rates, between the two techniques ${ }^{[4]}$

In our series, no complications were reported. With regards to the complications of $\mathrm{PD}$, the principal pitfall is an esophageal perforation rate of 2-6\% (depending on the series and technique) ${ }^{[5]}$, which leads to completion myotomy emergently, and the lack of long term efficacy compared with SM in most studies ${ }^{[6]}$

The role of injection of botulinum toxin injection (EBTI) versus pneumatic dilation is currently debated ${ }^{[7,8]}$. On the other hand, the role of PD compared to surgery still represents an area of uncertainty. A RCT examining SM versus PD showed equivalent results with regards to short-term efficacy, but in the long term patients who underwent SM had fewer recurrent symptoms than those treated with $\mathrm{PD}{ }^{[9]}$. Some studies (but not RCT) suggest that PD may achieve long- term relief of symptoms ${ }^{[10]}$ particularly in older patients $(>50$ years old) or when compared retrospectively with SM and, 
consequently, could be offered as a treatment in this subset of patients with achalasia ${ }^{[11]}$.

Many other studies in literature which concluded old age as a predictor of favorable outcome ${ }^{[12]}$. This is in contrast with our study; furthermore, a recent study ${ }^{[12]}$ showed that post-PD LES pressure measurement is useful to assess treatment response. Patients responding to the first session and those with post-PD LES pressure $<10 \mathrm{mmHg}$ tended to recur less, independently of sex and age, however not considering other clinical data.

Patients who have had treatment for achalasia typically have their response measured by improvement of their symptoms. However, more objective testing for response had been suggested. Manometrically, an LES pressure $<10 \mathrm{mmHg}$ has been shown to be a precise indicator of a successful SM [13].

\section{Conclusion}

Treatment options for achalasia have traditionally included pharmacotherapy such as injections with EBTI, PD and SM. Although the last two are considered the mainstay of treatment because of higher success rates and relative long-term efficacy compared to pharmacotherapy and EBTI, they both are associated with a perforation risk of about $1 \%$. SM is the most invasive of the procedures, but requiring laparoscopy and surgical dissection of the esophagogastric junction. Further studies are required to determine the cause of achalasia with identifying mechanisms that would facilitate medical intervention. Data arising from the literature show that peroral endoscopic myotomy (POEM) ${ }^{[14-17]}$ is a technique in evolution that does not have a strong evidence base at this time. Uncontrolled case series demonstrate that it can improve symptoms in patients with achalasia, but that side effects can occur commonly. Therefore, the use of POEM for treatment of esophageal achalasia is considered investigational.

In conclusion, further prospective studies, with a larger number of patients, are needed in order to assess the impact of PD in the clinical course of esophageal achalasia according to patients age, and estabilishing a correlation between clinical, radiological, functional and endoscopical data.

Up to now, the therapy of achalasia is based on relaxation or mechanical disruption of the LES. Due to the rarity of the disease, there are few randomized, controlled clinical trials (RCT) that can define the optimal strategy to treat achalasia, and consequently the safety, effectiveness, and durability of available treatment options vary widely.

\section{Conflict of interests}

none declared for all the authors

\section{References}

1. Wu JC. Pneumatic Dilation versus Laparoscopic Heller's Myotomy for Idiopathic Achalasia (N Engl J Med 2011;364:1807-1816). J Neurogastroenterol Motil. 2011Jul;17(3):324-6.

2. Kadakia SC, Wong RK. Graded pneumatic dilation using Rigiflex achalasia dilators in patients with primary esophageal achalasia. Am J Gastroenterol 1993;88:34-38.

3. Hulselmans M, Vanuytsel T, Degreef T, et al. Long-term outcome of pneumatic dilation in the treatment of achalasia. Clin Gastroenterol Hepatol 2010;8:30-35.

4. Chuah SK, $\mathrm{Hu} \mathrm{TH}, \mathrm{Wu} \mathrm{KL}$, et al. Clinical remission in endoscopeguided pneumatic dilation for the treatment of esophageal achalasia: 7-year follow-up results of a prospective investigation. J Gastrointest Surg 2009;13:862-867.

5. Reynolds JC, Parkman HP. Achalasia. Gastroenterol Clin North Am 1989;18:223-255.

6. West RL, Hirsch DP, Bartelsman JF, et al. Long term results of pneumatic dilation in achalasia followed for more than 5 years. Am J Gastroenterol 2002;97:1346-1351.

7. Leyden JE, Moss AC, MacMathuna P. Endoscopic pneumatic dilation versus botulinum toxin injection in the management of primary achalasia. Cochrane Database Syst Rev 2006:CD005046.

8. Campos GM, Vittinghoff E, Rabl C, et al. Endoscopic and surgical treatments for achalasia: a systematic review and meta-analysis. Ann Surg 2009;249:45-57.

9. Csendes A, Braghetto I, Henriquez A, et al. Late results of a prospective randomised study comparing forceful dilatation and oesophagomyotomy in patients with achalasia. Gut 1989;30: 299-304.

10. Vela MF, Richter JE, Khandwala F, et al. The long-term efficacy of pneumatic dilatation and Heller myotomy for the treatment of achalasia. Clin Gastroenterol Hepatol 2006;4:580-587.

11. Francis DL, Katzka DA. Achalasia: Update on the Disease and Its Treatment. Gastroenterology 2010;139:369-374

12. Ghoshal UC, Rangan M, Misra A. Pneumatic dilation for achalasia cardia: reduction in lower esophageal sphincter pressure in assessing response and factors associated with recurrence during long-term follow up. Dig Endosc. 2012

13. Jan;24(1):7-15.Eckardt VF, Aignherr C, Bernhard G. Predictors of outcome in patients with achalasia treated by pneumatic dilation. Gastroenterology 1992;103:1732-1738.

14. Von Renteln D, Fuchs KH, Fockens P et al. Peroral endoscopic myotomy for the treatment of achalasia: an international prospective multicenter study. Gastroenterology 2013; 145(2):309-11 e3.

15. Ren Z, Zhong Y, Zhou P et al. Perioperative management and treatment for complications during and after peroral endoscopic myotomy (POEM) for esophageal achalasia (EA) (data from 119 cases). Surg Endosc 2012; 26(11):3267-72.

16. Zhou PH, Li QL, Yao LQ et al. Peroral endoscopic remyotomy for failed Heller myotomy: a prospective single-center study. Endoscopy 2013; 45(3):161-6. 
Abdomen 2015; 2: e512. doi: 10.14800/Abdomen.512; @ 2015 by Emanuele Sinagra, et al.

http://www.smartscitech.com/index.php/Abdomen

17. Li QL, Chen WF, Zhou PH et al. Peroral endoscopic myotomy for the treatment of achalasia: a clinical comparative study of endoscopic full-thickness and circular muscle myotomy. J Am Coll Surg 2013; 217(3):442-51. 